\title{
Influence of Breechblock Operating Force on Work of Shock Test Bed for Gun Breechblock System
}

\author{
Yanfeng Yang ${ }^{1, \mathrm{a}}$, Jian Zheng ${ }^{1}$, Changchun $\mathrm{Di}^{1}$, Dalin $\mathrm{Wu}^{1}$, Dong Wang ${ }^{2}$ \\ ${ }^{1}$ Mechanical Engineering College, Shijiazhuang, China \\ ${ }^{2}$ A A institute, Beijing, China \\ ${ }^{a}$ E-mail address: yyf2012yyf@163.com
}

Keywords: Breechblock system; Shock test bed; Simulation; Breechblock operating force

\begin{abstract}
For it is hard to develop experiments for the gun breechblock system, a shock test bed is designed for it. During designing, the breechblock operating force is one of the key test parameters of the shock test bed for gun breechblock system. In order to choose a reasonable value to open breechblock, influence of breechblock operating force on breechblock operating works of shock test bed is analyzed. With the design principle determined, the dynamics principle model of the shock test bed is established based on the virtual prototype technology. According to the minimum theoretical force $F$, a standard value for shock test bed to open breechblock. As both the mass of breechblock operating cam and the breechblock operating distance are fixed, the simulation experiments are performed based on the principle model when the breechblock operating force is $F$, $1.5 F, 2 F, 2.5 F$ and $3 F$ separately. The results show that the greater breechblock operating force is, the more total work, useful work and useless work have been done. But the wasted energy of work will increase. By the research, it is better to choose a less value of breechblock operating force.
\end{abstract}

\section{Introduction}

More experiments for the study of gun shooting are so destructive that some key physical quantities cannot be measured directly. In addition, such experiments cost a lot of manpower and material resources so that finding experimental data has proven difficult. However, correlative experiment studies are necessary to examine design indexes of gun in development and design. As a result, treating the breechblock system separately to establish test bed is put forward. Using the test bed to do experiments and examine design indexes will go well.

Virtual Prototyping(VP) technology has been applied more and more to dynamics analysis[1], fault analysis[2], capability and reliability studying[3][4] and so on. So such technology is beneficial to design shock test bed for breechblock system before establishing physical test bed. In this paper, VP technology is used to perform simulation experiments, so as to analyze the influence of breechblock operating force on works of shock test bed.

\section{Design of shock test bed for breechblock system}

\section{Design principle}

The breechblock system consists of gun breech, breechblock and other parts installed on the two parts. The process of opening and closing breechblock is breechblock moving down and up along gun breech. The other parts use the motion to complete their design actions. Based on research, design principle of shock test bed is adopting breechblock operating cam, the moving part, to impact crank lever, with gun breech fixed on the test bed. In this way, it is availably to reduce the mass and driving energies, which can facilitate the construction of shock test bed. The principle is shown in Figure 1. During test bed designing, breechblock operating cam is fixed on a case. The case is loaded with mass bodies. The total mass to impact crank lever will be changed through varying the numbers of mass bodies. The force, on the breechblock operating cam, is supplied by hydraulic pressure, which is the breechblock operating force to open breechblock. 


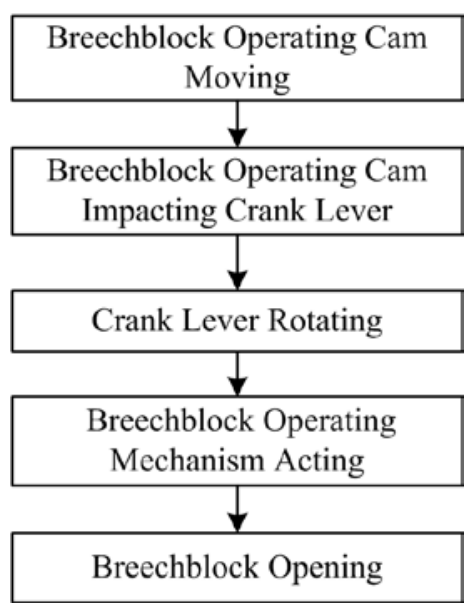

Fig.1. Breechblock opening principle of the shock test bed.

\section{Model establishment of shock test bed}

The principle model of shock test bed for breechblock system is established based on virtual prototype technology. The three-dimensional solid model is established by software Pro/E. Then it is imported into the dynamic software ADAMS and added some constraints and force. In the model, gun breech is fixed on the ground without motion. The breechblock operating cam is defined a motion and a force on it. Then the breechblock operating cam could move along the opposite direction of gun breech to impact crank lever under the force. In the software ADAMS, it is easy to change the breechblock operating force.

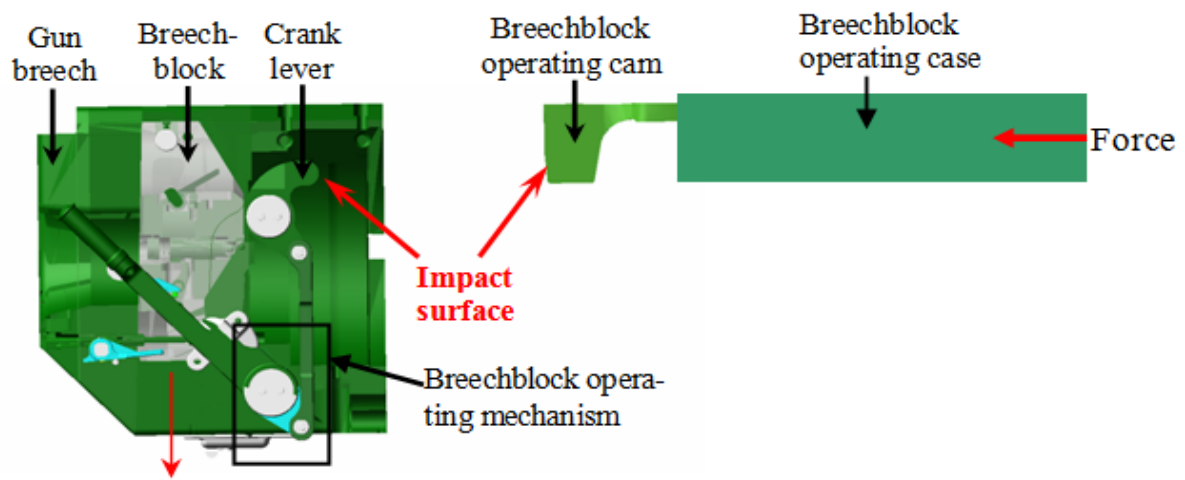

Fig.2. The virtual prototype model of the shock test bed for breechblock system.

With the definite breechblock operating distance $(S=400 \mathrm{~mm})$, the kinetic energy theorem is used to calculated the theoretical value of minimum breechblock operating force[5]. That is

$$
F=518.2 \mathrm{~N}
$$

The minimum breechblock operating force provides a standard for choice of breechblock operating force. That is to say, when the breechblock operating force is smaller than $F$, the test bed can not open breechblock.

\section{Simulation experiment}

Based on the principle model of shock test bed, the influence of breechblock operating force on works is studied through simulation experiments. For the light mass $(m)$ of breechblock operating cam is about $2 \mathrm{~kg}$, it is necessary for the shock test bed to increase the breechblock operating momentum by changing the breechblock operating cam's mass in simulation. To study the influence of breechblock operating force on breechblock operating works, the mass of breechblock operating cam is chosen $10 \mathrm{~m}$ and the breechblock operating distance is constant $(\mathrm{S}=400 \mathrm{~mm})$. Simulation experiments are performed when the breechblock operating force is $F 、 1.5 F 、 2 F 、 2.5 F 、 3 F$ separately.

In order to calculate work of breechblock operating force under different conditions, it is 
necessary to test breechblock displacement, spring deformation, maximum displacement of breechblock operating cam and other parameters. Figure 3 shows the curves of breechblock operating cam's displacement under different working conditions. For the breechblock operating force at $2.5 F$ and $3 F$ could open breechblock, breechblock operating distance is adopted as the maximum displacement of breechblock operating cam in work calculation.

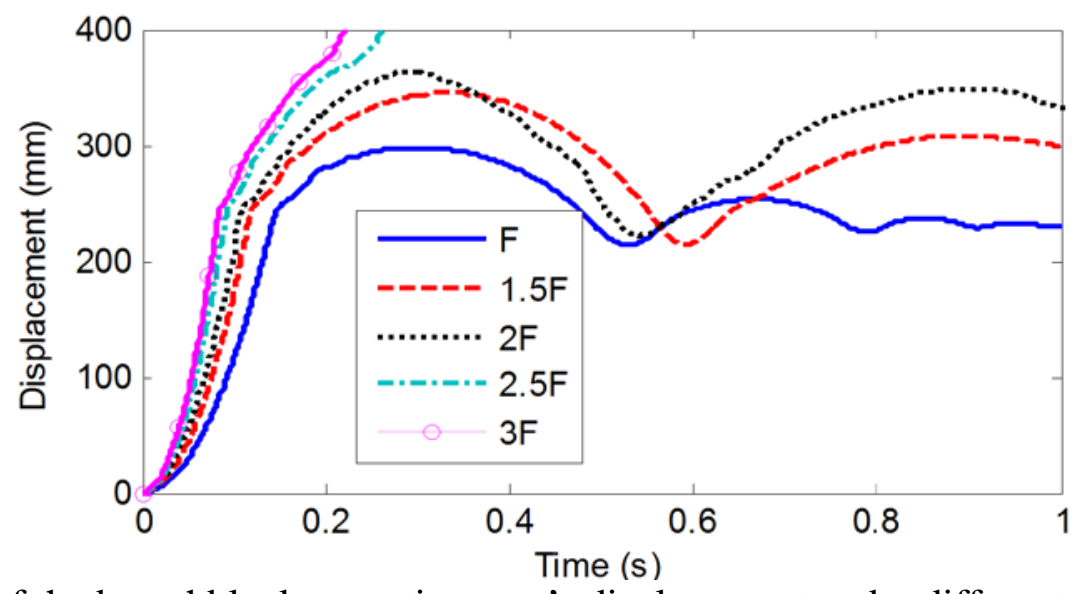

Fig.3. Curves of the breechblock operating cam's displacement under different working conditions.

By calculation, total work of breechblock operating force, useful work (increased energy of system) and useless work are obtained and shown in Table 1.

Table 1 . Work of the force.

\begin{tabular}{ccccc}
\hline \multirow{2}{*}{$\begin{array}{c}\text { Breechblock } \\
\text { operating force }\end{array}$} & \multirow{2}{*}{$\begin{array}{c}\text { Maximum displacement of } \\
\text { breechblock operating cam (m) }\end{array}$} & & \multicolumn{3}{c}{ Work(J) } \\
\cline { 3 - 5 } & 297.7 & Total work & $\begin{array}{c}\text { Useful } \\
\text { work }\end{array}$ & $\begin{array}{c}\text { Useless } \\
\text { work }\end{array}$ \\
\hline$F$ & 345.3 & 154.3 & 62.7 & 91.6 \\
$1.5 F$ & 363.3 & 268.4 & 128.5 & 139.9 \\
$2.0 F$ & 400.0 & 376.6 & 167.2 & 209.4 \\
$2.5 F$ & 400.0 & 518.2 & 232.4 & 285.8 \\
$3.0 F$ & 621.8 & 247.7 & 374.1 \\
\hline
\end{tabular}

Table 1 shows that the greater breechblock operating force is, the more total work, useful work and useless work have been done. Furthermore, useless work is greater than useful work. The increase of useful work means that the greater breechblock operating force is, the more beneficial it is to open breechblock. However, the increase of useless work means that the greater breechblock operating force is, the more energy is wasted during impact. And the wasted energy exceeds half of total work. Under the breechblock operating force $3 F$, the percentage of wasted energy achieves $60.2 \%$.

To analyze the influence rules on work, the data in Table 1 are plotted in Figure 4.

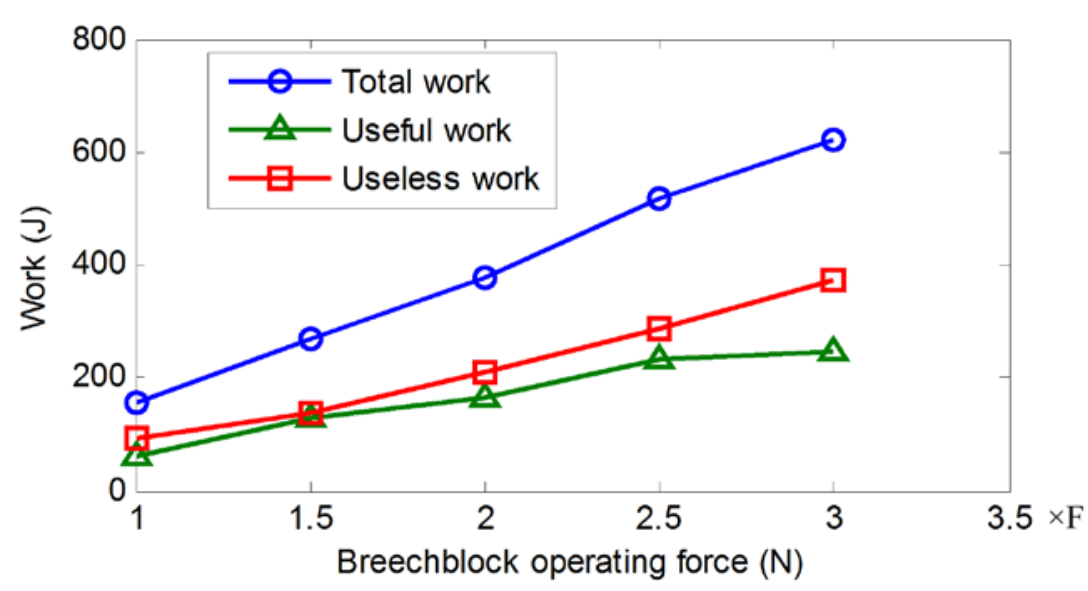

Fig.4. Rules of the work of the breechblock operating force. 
In Figure 4, as breechblock operating force increases, both total work curve and useless work curve ascend in rectilinear trend, but useful work curve ascends gently. That is to say, the greater breechblock operating force is, the more diminutively it influences useful work. And the influence on total work and useless work remain unchanged. Under the breechblock operating force $2.5 F$ and $3 F$, the test bed could make opening breechblock come true, so the increased energies of breechblock system without breechblock operating cam are equal. However, the kinetic energy of breechblock operating cam increases, so the useful work curve ascends. And the increased energies of system are primary and greater than the kinetic energy of breechblock operating cam, so the useful work curve goes gently.

\section{Conclusion}

In this paper, as both the mass of breechblock operating cam and the breechblock operating distance are certain, simulation experiments are performed based on the principle model when the breechblock operating force is $F, 1.5 F, 2 F, 2.5 F$ and $3 F$ separately. The results show that the greater breechblock operating force is, the more total work, useful work and useless work have been done. Nevertheless, the wasted energy increases during the work of the force. In a word, it is better to choose a less value of breechblock operating force under the prerequisite of ensuring opening breechblock. The study provides theoretical reference for test bed establishment and experiments.

\section{Acknowledgment}

The author wishes to thank all colleagues who previously provided technical support.

\section{References}

[1] Hua BB, Ma JS, Deng HY, et al. Firing dynamic response analysis of a self-propelled artillery fire system based on virtual prototype technology. New Technology \& New Process 2013; (3):46-48.

[2] Zhang JB, Cheng L, Hu HB, et al. Research on fault simulation technology based on virtual prototype for recoil system. Computer Measurement \& Control 2012; 20(5):1287-1289.

[3] Cui QB, Zhang JZ, Xue GH, et al. Fatigue life prediction of gear based on simulation technology. Key Engineering Materials 2006; 324-325:431-434.

[4] Li W, Ma JS, Di CC, et al. Simulation Research on Dynamics of Ramming System and Action Reliability Considering the Randomness of the Parameters. Acta Armamentarii, 2012, 33(6):747-752.

[5] Yang YF, Zheng J, DI CC, et al. Shock test platform design of gun breech system based on kinetic energy theorem. Explosion and Shock Waves, 2015, 35(1): 76-81. 